Annals of the

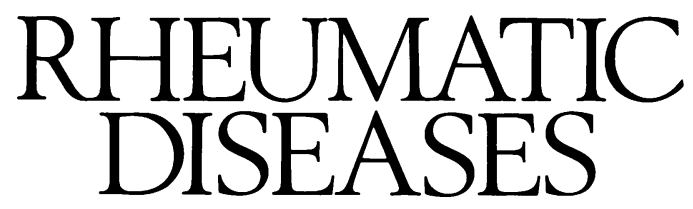

Leaders

\section{From Truro to Nottingham}

On 1 April the editorial office of the Annals moved to Nottingham and a new editorial board started their term of office. Over the past three years Tony Thould has steered the Annals from the rheumatology unit in Truro; he has taken the journal to its larger size and $B M \mathcal{F}$ format, introduced features such as the Heberden papers, dispatch, and masterclass, and edited the 50th (volume) anniversary issue. His hard work and commitment are widely recognised, and he can be justifiably proud of helping the Annals to progress along a sound evolutionary trail. ${ }^{1}$

Although the journal continues to flourish, there have been problems in the past year. Firstly, with the processing of submitted papers, and, secondly, with delay in the publication of accepted papers. These problems, of course were mainly perceived by contributors. The reasons for both are multiple, but include a large volume of submitted work, difficulties inherent in operating multiple peer review within a small specialty, and a relatively high acceptance rate for original papers. For some submitting authors delays in processing have been extreme and communication has proved difficult. Understandably, for some authors confidence in the Annals has been shaken.

If a 'mission statement' for 1992-3 were to be issued by the new editorial board the following priorities would be emphasised:

(1) provision of an efficient, professional processing service for submitting authors, and

(2) reduction of the publication time to under six months. Additional priorities within the next year include:

(3) an increase in the regular postgraduate educational component of the journal,

(4) an increase in 'reader involved' diagnostic cases, and

(5) enhancement of the relevance and profile of the Annals within Europe.

A continuing aim, of course, is for the Annals to continue as a premier vehicle for dissemination of clinical and laboratory based research and as a forum for comment related to rheumatology.

Various steps have already been taken to realise these goals. The Nottingham office has an experienced editorial assistant in place (Prue Napthine), dedicated telephone and fax lines to facilitate communication with the editor (see inside back cover), and several 'failsafe' strategies to streamline the paper tracking and review process. The journal will continue its 'fatter' issues for several more months and lose the editor's resumé and encore as measures to 'catch up' quickly on publication time of processed papers. As a longer term measure the maintenance of high standards and short publication time for papers will depend on the modified review process with its monitored (higher than previous) rejection rate.

It is no accident that the newly formed editorial board has the youngest mean age in the history of the Annals (30 to 40 'something'). Each individual was chosen because of their proven track record of academic distinction and energy. Rather than being just prestigious figure heads on the inside cover, each will play an active part in determining the content and style of the Annals. For the first time rheumatologists from outside the United Kingdom and a trainee representative are included as full members (the trainee as a non-reviewing advisor). Through the board's concerted actions, a number of new series and regular features will begin to appear later this year, hopefully offering continuing variety and interest in each issue. Feedback from regular readers of the Annals will be actively sought and always welcome.

Although rapid advances in communication technology have questioned the future of 'hard copy' specialist journals, it seems that their value for commentary and continuing education is even greater. The board are aware that the Annals must continue to adapt to meet that requirement, building on its existing strong foundations.

A more specific question is the role of the Annals as one of two rheumatology journals based in the United Kingdom. ${ }^{13}$ In agreement with the editor of the British fournal of Rheumatology, ${ }^{3}$ we believe that both journals justify a place in the rheumatology world. ${ }^{1}$ The 'green journal' is half owned by the British Society for Rheumatology and acts as its official outlet-it is therefore fitting that 'British' remains eminent in its title. The Annals equally is proud to be owned by, but editorially separate from, the British Medical Association. It thus shares the $B M \mathcal{M}$ 's tradition of specialist journal independence, being free from restrictions relating to publishing profits and existing solely for the purposes of education and academic advancement. With this background the Annals of the Rheumatic Diseases intends to continue to provide interest and set standards within the clinical and scientific community of rheumatology, of relevance not just to Europe but also the world.

\section{MICHAEL DOHERTY}

1 Scott J T. A note on the history of the journal. Ann Rheum Dis 1991; 50: $510-1$

2 Lock S. Future of specialist journals. Ann Rheum Dis 1991; 50: 460-1.

3 Bird H. An expanding journal. Br $\mathcal{J}$ Rheumatol 1992; 31: 1-2. 